\title{
ARE PERSON CATEGORIES USED WHEN ORGANIZING INFORMATION ABOUT UNFAMILIAR SETS OF PERSONS?
}

\author{
CONSTANTINE SEDIKIDES \\ University of Wisconsin-Madison
}

THOMAS M. OSTROM

Ohio State University

It has long been tacitly assumed that perceivers spontaneously organize social information, such as traits and behaviors, into individualized person gestalts. The validity of this assumption was questioned in research by Ostrom and Pryorthat examined how perceivers organize information in multiperson, multiattribute perceptual fields (e.g., a party, a group discussion, or a criminal trial setting). Their data indicated that in such situations social information about unfamiliar others is not organized around persons. This paper reports a meta-analysis of 44 published and unpublished person organization studies. This increase in statistical power afforded by meta-analysis led to a rejection of Ostrom and Pryor's earlier conclusions. Perceivers were found to have a significant (although not large) tendency toward organizing social information around person categories, thus supporting the assumption of the early impression formation theorists.

Social psychological research has shown continued interest in the dynamics of impression formation processes. In the traditional impression formation experiment, subjects are presented with traits and/or behaviors about a stimulus person and are then asked to make an evaluative judgment about that person. This paradigm has been useful in identifying various determinants of initial impressions, such as order of presentation of trait items, set size, and trait centrality (Anderson, 1962, 1981; Asch, 1946; Wishner, 1960).

This earlier research was guided by the assumption that when learning items of information (i.e., traits) about a stimulus person,

We are grateful to Charlie Bond for his advice on meta-analytic issues. We thank Craig Anderson, Matthew Berent, David Boninger, Jon Krosnick, and Kerry Marsh for helpful comments on an earlier draft of this manuscript. Appreciation is also extended to David Schneider, Brian Mullen, and an anonymous reviewer for their insightful suggestions. Computational facilities were provided by the Instruction and Research Computer Center at Ohio State University. Requests for reprints should be sent to Constantine Sedikides, Department of Psychology, University of Wisconsin, 1202 West Johnson Street, Madison, WI 53706. 
perceivers will automatically associate those items with the stimulus person. Further, it was assumed that items of information learned about another person will form a unique perceptual unit or gestalt. This gestalt would in turn influence the interpretation of all subsequent information by making it consistent with the initial impression.

More recent research has directly dealt with structural issues of impression formation. Work on implicit personality theory (e.g., Schneider, 1973) has shown that certain traits are related and well organized in the perceiver's mind. Research on cognitive schemata (e.g., Wyer \& Gordon, 1984) has provided data consistent with the operation of organized knowledge structures that affect social perception in a variety of ways. A part of these organized knowledge structures can be thought of as person schemas (Fiske \& Taylor, 1984). Person schemas have been found to bear encoding, representational, and inferential functions (Taylor \& Crocker, 1981).

Associative network theories of human memory (Anderson, 1983; Anderson \& Bower, 1973; Kintsch, 1974) provide the language for conceptualizing the structure of a person schema. When presented items of information attributed to a stimulus person, subjects form a person node in memory. Associative links are created between person nodes and the attributes of the stimulus persons. Hence, all traits would become related to each other by virtue of their associative links to the person node (for an associative model of memory for groups of persons, see Ostrom, Pryor, \& Simpson, 1981).

The assumption made by the early impression formation theorists (Anderson, 1962,1981; Asch, 1948; Heider, 1958) that person information is spontaneously encoded as a unified whole can be rephrased using the language of associative network theorists. The early theorists' view is consistent with arguing that social information is effortlessly and nondeliberatively organized into person schemas or person categories in memory. Persons serve as "natural categories" (cf. Rosch, 1973) for organizing information in social settings.

Whether information about people is organized in memory around person gestalts (or person schemas) is a fundamental issue in social psychology. The organization of social information into person categories in memory is a necessary precondition for various person perception processes. Impression formation, inferences, attributions, and memory for incongruent information all depend on the perceiver having formed a cognitive unit representing the person. If alternative information structures are established in memory (e.g., organizing social information by temporal, location, or descriptor referents), then the ensuing social responses can be quite different.

Ostrom, Pryor, and colleagues (Ostrom, Pryor, \& Simpson, 1981; Pryor \& Ostrom, 1981) challenged the early assumption that persons 
act as natural categories. They proposed that the assumption is questionable when the perceiver is in a multiperson stimulus setting that consists entirely of unfamiliar others. Examples might be social gatherings, committees, criminal trial settings, or when reading about characters in a novel. In a series of studies on multiperson stimulus arrays, Ostrom and Pryor explored the idea that individuals employ diverse strategies when organizing social information. A person-based organizational strategy, they hypothesized, is only one of many.

Person organization research is concerned with the extent to which social information is clustered in memory around persons. Subjects' categorization of stimulus information in free recall has been assessed via a clustering measure known as the Adjusted Ratio of Clustering (or ARC; Roenker, Thompson, \& Brown, 1971). One attractive feature of this index is that it has a rational zero point. An index of zero means that the order in which items are listed by the subjects in free recall is totally random in terms of which persons (from the multiperson, multiattribute stimulus field) they describe. A significant positive deviation from zero is taken to reflect the use of person categories in encoding and/or retrieving this information from long-term memory.

In the early person organization research, no significant clustering according to persons was found for unfamiliar targets. In a study by Pryor and Ostrom (1981, study 3), subjects exhibited a mean ARC score of .175 in their free-recall protocols that followed the first stimulus presentation of unfamiliar targets. This ARC score was not significantly different from zero. Similarly, Pryor, Simpson, Mitchell, Ostrom, and Lydon (1982) reported ARC scores of .070 (study 1), -.030 (study 2), and .010 (study 3), none of which differed significantly from chance.

Based on these findings, Ostrom, Pryor, and colleagues concluded that person categories were not spontaneously used to organize information about unfamiliar persons. They stated that "unfamiliar information about strangers is not organized in recall according to persons" (Ostrom, Pryor, \& Simpson, 1981, p. 24), that "social information is not organized by person when the stimulus persons are completely unfamiliar" (Pryor \& Ostrom, 1981, p. 628), and that "unfamiliar persons were not used in organizing the retrieval of social information" (Pryor et ah, 1982, p. 343).

If social information is not organized around persons, then how is it organized? Among the possibilities are knowledge or descriptor categories (e.g., occupation, hobby, hometown, or academic major), trait categories (e.g., friendly, extraverted, or intelligent behaviors), and spatial/temporal categories (e.g., location, time of day, or day of the week). Indeed, Pryor et al. (1982, p. 336) concluded that "with unfamiliar persons, subjects manifest a distinct preference for descriptorbased organization over person-based organization." 


\section{A META-ANALYTIC APPROACH TO PERSON ORGANIZATION}

A substantial number of studies on person organization have been conducted since 1979 that are relevant to the conclusions reached in the above noted papers. In the light of this accumulated empirical evidence, the issue of whether we organize our social milieu in terms of persons needs to be reconsidered. This work reports a meta-analysis of those studies in order to provide a more definitive answer to two questions regarding person-based organization.

First, is there a significant tendency to use person organization when the stimulus domain is composed of unfamiliar stimulus persons? Second, when information about unfamiliar stimulus persons can be classified into a limited number of descriptor categories, do subjects tend to organize information by persons or by descriptor categories?

\section{THE PROTOTYPIC PERSON ORGANIZATION STUDY}

The prototypic person organization study is a laboratory experiment where subjects are presented with information about a number of stimulus persons, are requested to make impression ratings of them, and, after a brief distractor task, to recall the information. The information is provided in the form of sentences describing some characteristic (e.g., trait, hobby, occupation, or behavior) of the stimulus person.

The name of the stimulus person always accompanies the descriptor phrase (e.g., John is independent). The descriptors may themselves fall into a set of categories independent of (i.e., orthogonal to) the person categories. For example, the descriptor phrases "Sandra enjoys woodcarving," "Tina enjoys fishing," and "Lisa enjoys listening to music" all fall in the category of "hobbies." In this case, descriptor categories compete with person categories for gaining subjects' organizational preference. Hence, studies containing both descriptor categoriesandpersoncategories are termed competing categoriesstudies.

Alternatively, the descriptor phrases may not fall in category sets, as in the following example: "Sandra is intelligent," "Sandra enjoys woodcarving," "Sandra's major is architecture." In such cases, only person categories are salient, Subjects can either organize the social information by person or in some more idiosyncratic manner. We have termed such studies person category studies.

$A$ dependent measure common to all these studies is the degree of clustering by person (person ARC score). An additional ARC score is computed in the competing categories studies. It is the degree of clustering by descriptor category (descriptor ARC score). 
ARC scores typically range from 0 to 1 , with 0 indicating chance clustering and 1 indicating perfect clustering. A negative ARC score indicates that the subject is organizing information in a way contrary to the coding scheme. ARC has been recognized as the "single most desirable index of order information in free recall currently available" (Srull, 1984, p. 9).

\section{SAMPLE OF STUDIES USED IN THE META-ANALYSIS}

Forty-four studies were included, involving the participation of 2,786 subjects. (The studies are presented in the Appendix.) The earliest study was dated 1979 and the latest 1987. The 44 studies were composed of published reports, papers presented at conventions, master's theses, dissertations, and unpublished manuscripts.

We observed the following five criteria in selecting person organization studies for inclusion in the meta-analysis. One, the study should employ unfamiliar stimulus persons. Two, the study should present subjects with multiple stimulus persons; thus, studies like the ones conducted by Hamilton, Katz, and Leier (1980) were excluded because the stimulus field was occupied by only one person. Three, the study should provide ARC scores; this criterion excludes studies that used other measures of cognitive organization (e.g., Srull \& Brand, 1983). Four, the study should not involve repeated presentation of the stimulus person information prior to recall. Five, when the study involves multiple presentation of the same stimulus person information, only the ARC scores associated with the first presentation should be used.

We searched psychological abstracts for person organization studies. AH studies but one satisfying the above five criteria were conducted by Ostrom, Pryor, and their colleagues. The exception was a study reported by Cafferty, DeNisi, and Williams (1986, study 2). The present sample of studies includes all relevant studies carried out either in Ostrom's or Pryor's laboratory.

\section{DATA EXTRACTED FROM EACH STUDY}

All 44 studies provided an ARC score for clustering in free recall on the basis of person categories. These data were used to determine whether the use of person categories was greater than chance. A subset of 26 studies employed a competing categories design. For those studies, both person ARC scores and category ARC scores were available. These data allowed us to determine whether person categories were used less than other descriptor categories. 
To address the first question (whether there is person organization at all for unfamiliar stimulus persons), we looked at the $p$ value for the one-sample $t$ comparing the mean person ARC score to 0. Each effect was computed as a standard normal deviate $(\mathrm{Z}=$ the value in the standard normal distribution corresponding to the one-tailed $p$ value of the effect; Rosenthal, 1978). Then we computed the weighted Stouffer meta-analytic standard normal deviate (i.e., $2_{\mathrm{ma}}$; Rosenthal, 1978). The latter statistic was used to determine a combined probability value for each effect. $Z_{\mathrm{ma}}$ was then tested for statistical significance. Finally, we computed the Fail-safe $N$, which refers to the number of null effects needed to reduce a statistically significant meta-analytic effect to nonsignificance. Rosenthal (1979) suggested that as a rule of thumb a Fail-safe $N$ that exceeds $5 \mathrm{k}+10$ (where $K$ is the number of reported effects) reflects a reliable meta-analytic effect. The following formula was used: Fail-safe $\left.N=\left((2 Z)^{2} / 2.706\right)-\mathrm{K}\right)$, for $p<.05$.

To address the second question (whether category organization prevails over person organization in the case of unfamiliar stimulus persons), we first computed the difference between the mean person ARC score (PARC) and the mean descriptor ARC score (DARC) for each study as a standardized difference between marginal means,

$$
g=\left(M_{\text {PARC }}-M_{\text {DARC }}\right) / S_{\text {pooled }}
$$

(Hedges, 1981) where $S_{\text {poo }}$ ied $=S$ for MPARC and MDARC- This is because the studies all employed a repeated measures design, involving a person ARC score and a category ARC score. Then we computed the mean $g(\overline{\mathrm{g}})$ to obtain an effect size estimate (Rosenthal, 1984, p. 78). Next we performed a test of significance for the difference between the means, as recommended by Hedges and Olkin (1985, p. 113). We also computed a test statistic for the heterogeneity of effect sizes (a diffuse comparison Chi-square; Rosenthal, 1984, p. 78). With this statistic we could test for inconsistencies across studies regarding the effect. Finally, we computed the Fail-safe $N$.

All analyses were weighted by sample size.

\section{RESULTS}

\section{QUESTION 1: IS THERE PERSON ORGANIZATION FOR UNFAMILIAR STIMULUS PERSONS?}

A meta-analysis was performed on the 44 studies appearing in Table 1. A significant meta-analytic $\mathrm{Z}\left(\mathrm{Z}_{\mathrm{ma}}=11.36, p<.001\right)$ revealed that unfamiliar persons are indeed organized on a person by person basis. 
TABLE 1

Person Organization of Unfamiliar Stimulus Persons

\begin{tabular}{|c|c|c|c|}
\hline STUDY & $\mathrm{N}$ & PERSON ARC & $\mathrm{Z}$ \\
\hline Carpenter \& Ostrom (1985) & 96 & .107 & 1.14 \\
\hline Cafferty et al. (1986) & 125 & .157 & 3.30 \\
\hline Devine \& Ostrom (1985), study 1 & 96 & .234 & 3.32 \\
\hline Devine \& Ostrom (1985), study 2 & 48 & .395 & 3.95 \\
\hline Devine \& Sedikides (1986) & 144 & -.022 & -0.49 \\
\hline Devine et al. (1987) & 80 & .182 & 2.37 \\
\hline Herren (1985), study 1 & 96 & .241 & 1.39 \\
\hline Herren (1985), study 2 & 90 & .577 & 3.44 \\
\hline Lynn et al. (1985) & 32 & .140 & 3.91 \\
\hline McCann et al. (1983) & 80 & .212 & 4.90 \\
\hline McCann et al. (1985) & 32 & .149 & 4.03 \\
\hline Mitchell (1982), study 1 & 54 & .320 & 1.75 \\
\hline Mitchell (1982), study 2 & 24 & .450 & 2.07 \\
\hline Mitchell (1982), study 3 & 60 & .270 & 2.33 \\
\hline MitcheU et al. (1981a) & 20 & .510 & 1.88 \\
\hline Mitchell et al. (1981b) & 60 & .327 & 1.66 \\
\hline MitcheU et al. (1981c) & 48 & .007 & 0.06 \\
\hline Ostrom et al. (1986) & 36 & .132 & 2.38 \\
\hline Ostrom et al. (1986), study 2 & 32 & .210 & 3.10 \\
\hline Ostrom et al. (1986), study 3 & 113 & .330 & 2.32 \\
\hline Ostrom et al. (1984), study 1 & 32 & .270 & 2.68 \\
\hline Ostrom et al. (1984), study 2 & 68 & .550 & 3.28 \\
\hline Pfeifer et al. (1982) & 40 & .049 & 1.02 \\
\hline Pryor (1986) & 72 & .128 & 2.09 \\
\hline Pryor et al. (1984) & 60 & .286 & 2.62 \\
\hline Pryor \& Ostrom (1981), study 3 & 48 & .175 & 1.84 \\
\hline Pryor et al. (1982), study 1 & 32 & .045 & 0.12 \\
\hline Pryor et al. (1982), study 2 & 64 & -.030 & -0.63 \\
\hline Pryor et al. (1982), study 3 & 48 & .010 & 0.12 \\
\hline Pusateri (1984), study 1 & 102 & .228 & 4.63 \\
\hline Pusateri (1984), study 2 & 32 & .338 & 3.60 \\
\hline Pusateri (1984), study 3 & 76 & .057 & 0.77 \\
\hline Pusateri (1984), study 4 & 72 & .007 & 0.05 \\
\hline Pusateri \& Geva (1985) & 40 & .418 & 4.51 \\
\hline Pusateri \& Ostrom (1984) & 48 & .149 & 1.50 \\
\hline Pusateri et al. (1984), study 1 & 40 & .317 & 3.87 \\
\hline Pusateri et al. (1984), study 2 & 60 & .041 & 0.93 \\
\hline Sedikides \& Ostrom (1986a) & 64 & .020 & 0.19 \\
\hline Sedikides \& Ostrom (1986b) & 160 & .142 & 0.77 \\
\hline Sedikides \& Ostrom (1986c) & 56 & .078 & 0.89 \\
\hline Sedikides \& Ostrom (1987) & 80 & .505 & 3.80 \\
\hline Simpson (1979), study 2 & 32 & .110 & 0.90 \\
\hline Simpson (1979), study 3 & 24 & .005 & 0.02 \\
\hline Simpson (1979), study 4 & 70 & -.060 & -0.69 \\
\hline
\end{tabular}


A large Fail-safe $N(N=2797)$ also attested to the reliability of the effect. The median person ARC score over all 44 studies was .166.

This finding refutes the conclusions reached by Ostrom, Pryor, and Simpson (1981), Pryor and Ostrom (1981), and Pryor et al. (1982). A consideration of all available data makes it clear that person categories will be spontaneously used to organize information about unfamiliar persons. As Table 1 shows, only three of the 44 studies produced person ARC scores below the chance level of zero.

It might be expected that this tendency for person organization would hold in person category studies because in such studies person categories provide the only structure available in the stimulus field. However, this tendency may not occur in competing categories designs, where person categories and descriptor categories are equally prominent.

To test this possiblity, we meta-analyzed the person category studies separately from the competing categories studies. The metaanalytic $\mathrm{Z}$ was significant in both cases $\left(\mathrm{Z}_{\mathrm{ma}}=8.94, \mathrm{p}<.001\right.$, and $\mathrm{Z}_{\mathrm{ma}}=8.24, p<.001$, respectively, with Fail-safe N's of 583 and 801). The difference between these two meta-analytic Z's was not significant ( $\mathrm{Z}=.495, p=\mathrm{n} . \mathrm{s}$.) as assessed by a focused-contrast comparison (Rosenthal, 1984, p. 89). Thus subjects tended to person organize social information both when the stimulus field consisted of person categories alone (median person ARC score $=.241$ ) as well as when it consisted of both person categories and descriptor categories (median person ARC score = .145).

\section{QUESTION 2: ARE GENERAL DESCRIPTOR CATEGORIES PREFERRED TO PERSON CATEGORIES?}

This question was addressed by meta-analyzing the person ARC and category ARC scores for the 26 competing categories studies. A nonsignificant meta-analytic $\mathrm{Z}\left(\mathrm{Z}_{\mathrm{ma}}=-.172, p=\right.$ n.s. $)$ and a weak mean weighted effect size $(\bar{g}=-.008)$ demonstrated that people do not prefer one organizational strategy over the other (Table 2). The median person ARC score was .145 and the median category ARC score was .142 .

The effect size showed a substantial level of heterogeneity $\left(\mathrm{x}^{2}\right.$ $(25)=98.56, p<.001$ ), meaning inconsistent or conflicting findings across studies. This heterogeneity may be due to the qualitative characteristics of different sets of competing categories. Some studies employed "social" categories (e.g., occupation, traits, hobbies), whereas others used "nonsotial" categories (or spatial/temporal categories, like 
TABLE 2

Comparing Person versus Descriptor Category Organization

\begin{tabular}{|c|c|c|c|c|}
\hline STUDY & $\begin{array}{l}\text { NATURE OF COMPETING } \\
\text { CATEGORY }\end{array}$ & $\begin{array}{l}\text { PERSON } \\
\text { ARC }\end{array}$ & $\begin{array}{l}\text { CATEGORY } \\
\text { ARC }\end{array}$ & G \\
\hline \multicolumn{5}{|l|}{ Carpenter \& } \\
\hline Ostrom (1985) & Social & .107 & .115 & -.01 \\
\hline $\begin{array}{l}\text { Cafferty et al., } 1986, \\
\text { study } 2\end{array}$ & Social & .157 & .150 & .02 \\
\hline $\begin{array}{l}\text { Devine \& Ostrom, } \\
1985, \text { study } 1\end{array}$ & Social & .234 & .280 & -.09 \\
\hline $\begin{array}{l}\text { Devine \& Ostrom, } \\
1985, \text { study } 2\end{array}$ & Social & .395 & .105 & .65 \\
\hline $\begin{array}{l}\text { Devine \& Sedikides } \\
\quad(1986)\end{array}$ & Social & -.022 & .348 & -.98 \\
\hline Devine et al. (1987) & Social & .182 & .192 & -.02 \\
\hline $\begin{array}{l}\text { Herren }(1985) \\
\text { study } 1\end{array}$ & Sodal & .241 & .313 & -.06 \\
\hline $\begin{array}{l}\text { Herren (1985), } \\
\text { study } 2\end{array}$ & Social & .577 & -.112 & .63 \\
\hline $\begin{array}{l}\text { Mitchell (1982), } \\
\text { study } 3\end{array}$ & Social & .270 & -.020 & .47 \\
\hline Ostrom et al. (1986) & Social & .132 & .036 & .43 \\
\hline $\begin{array}{l}\text { Ostrom et al. (1986), } \\
\text { study } 2\end{array}$ & Nonsocial & .210 & .011 & .81 \\
\hline $\begin{array}{l}\text { Ostrom et al. (1986), } \\
\text { study } 3\end{array}$ & Nonsocial & .330 & .020 & .29 \\
\hline Pryor (1986) & Social & .128 & .384 & -.71 \\
\hline $\begin{array}{l}\text { Pryor et al. (1982), } \\
\text { study } 1\end{array}$ & Social & .045 & .420 & -.25 \\
\hline $\begin{array}{l}\text { Pryor et al. (1982), } \\
\text { study } 2\end{array}$ & Social & -.030 & .440 & -.44 \\
\hline $\begin{array}{l}\text { Pryor et al. (1982), } \\
\text { study } 3\end{array}$ & Nonsocial & .010 & .230 & -.54 \\
\hline $\begin{array}{l}\text { Pusateri (1984), } \\
\text { study } 1\end{array}$ & Nonsocial & .228 & .030 & .60 \\
\hline $\begin{array}{l}\text { Pusateri (1984), } \\
\text { study } 2\end{array}$ & Nonsocial & .338 & .013 & .97 \\
\hline $\begin{array}{l}\text { Pusateri (1984), } \\
\text { study } 3\end{array}$ & Nonsocial & .057 & .236 & -.39 \\
\hline $\begin{array}{l}\text { Pusateri (1984), } \\
\text { study } 4\end{array}$ & Nonsocial & .007 & .151 & -.17 \\
\hline $\begin{array}{l}\text { Pusateri \& Ostrom } \\
\quad(1984)\end{array}$ & Nonsocial & .149 & .243 & -.20 \\
\hline $\begin{array}{l}\text { Sedikides \& Ostrom } \\
\text { (1986a) }\end{array}$ & Social & .020 & .250 & -.34 \\
\hline $\begin{array}{l}\text { Sedikides \& Ostrom } \\
\quad \text { (1986b) }\end{array}$ & Social & .142 & .041 & .09 \\
\hline $\begin{array}{l}\text { Sedikides \& Ostrom } \\
\text { (1986c) }\end{array}$ & Social & .078 & .133 & -.07 \\
\hline $\begin{array}{l}\text { Sedikides \& Ostrom } \\
\text { (1987) }\end{array}$ & Social. & .505 & -.140 & .98 \\
\hline $\begin{array}{l}\text { Simpson (1979), } \\
\text { study } 2\end{array}$ & Nonsocial & .110 & .060 & .10 \\
\hline
\end{tabular}


day of the week or location). Studies used either social or nonsocial categories. It is possible that social categories provide a more meaningful basis for grouping person characteristics than do nonsocial categories. Descriptions of different hobbies or food preferences hang together more than descriptions of different actions done on an arbitrary day of the week, like Tuesday. Consequently, we broke Question 2 down into two subquestions to determine whether the quality of the descriptor categories moderates the large heterogeneity of effects observed.

Are social descriptor categories preferred to person categories? A procedure identical to the one used in Question 2 was adopted to address this subquestion. No preference was found for person versus social category organization in the 17 studies meta-analyzed, $\mathrm{Z}=-1.07, p=$ n.s., weighted $\bar{g}=-.059$ (median person ARC score $=.142$, and median category ARC score $=.150$ ). The heterogeneity of effects remained large, $\mathrm{x}^{2}(16)=68.97, p<.001$.

Are nonsockl descriptor categories preferred to person categories? Again, no preference was found for nonsocial descriptor category organization over person organization in the nine studies meta-analyzed, $\mathrm{Z}=1.38$, $p-$ n.s., weighted $\tilde{g}-.12$ (median person ARC score $=.149$, and median category ARC score $=.060$ ). The heterogeneity of effects was still large, $) \mathrm{p}(8)=26.25, p<.001$. However, a focused-contrast comparison revealed that the last two meta-analytic Z's were significantly different from each other $\left(Z_{m a}=1.73, p<.05\right)$.

The results provided no support for the possibility that the quality of the descriptor category (i.e., social or nonsocial) moderated the heterogeneity of the effect sizes. Perceivers appear not to manifest an overall organizational preference for either descriptor categories or person categories when both are comparable in saliency. However, perceivers do appear to manifest a stronger tendency for descriptor category organization over person category organization when the descriptor category is composed of "social" items than "nonsocial" items.

\section{DISCUSSION}

Ostrom, Pryor, and colleagues (Ostrom, Pryor, \& Simpson, 1981; Pryor \& Ostrom, 1981; Pryor et ah, 1982) concluded that people do not spontaneously organize social information about unfamiliar persons in memory on a person-by-person basis, and that when an alternative mode of organization exists (e.g., social or nonsocial categories), it will prevail over person organization.

The present meta-analysis refutes those earlier conclusions. It was found that people tend to organize social information around 
persons even when confronted with unfamiliar others (and even when the confrontation involves reading about-rather than seeing and interacting with-the others). Thus the implicit assumption made by Asch (1946), Heider (1958), and Anderson $(1962,1981)$ that we spontaneously form a person gestalt when encountering unfamiliar people was supported.

Why is there a discrepancy between the early and the present conclusions? In all programmatic research there is a file drawer problem. The published studies may not fairly represent the entire population of published plus unpublished studies. Usually the problem is one in which the null hypothesis is rejected in the published studies and not rejected in the file drawer studies. Here we have the opposite case for Question 1. The earliest published studies could not reject the null hypothesis (i.e., nonuse of person categories in organizing person information), but the meta-analysis did.

To see whether there was selectivity in the papers that appeared in print, the median person ARC scores were calculated from Table 1 for the published studies and compared to that for the entire metaanalysis. Only a very small difference emerged: median (published studies $)=.153$; median (meta-analysis) $=.166$. There appears to be no bias on the part of either authors or editors in selecting results to publish on this point.

This leaves only one reason for the difference in conclusions. The meta-analysis brought far more power to bear on testing the hypothesis than did any one of the previously published studies. Our best estimate for the value of ARC for person organization from Table 1 is the median value of .166. This is actually smaller than the value of .175 reported in the original study by Pryor and Ostrom (1981), a value that was not significantly different from an ARC of zero. The revision in conclusions, then, resulted primarily from the statistical strength of the meta-analytic approach.

Determinants of the strength of person organization. The original studies on person organization were designed to test whether there was more use of person categories with familiar persons than with unfamiliar persons (Pryor \& Ostrom, 1981). Familiarity was indeed a potent determinant. The present analyses focus just on unfamiliar persons.

Table 1 shows the results of 44 studies. It must be recognized that these studies differed from one another in many ways. For example, the number of persons in the stimulus array varied from three to five, the number of competing categories varied from three to five, and the social referent could be an ingroup or an outgroup (or be unspecified).

It would be possible to extend the meta-analysis to examine the effects of such variables in this population of studies. We chose not 
to meta-analyze these variables for two reasons. First, there was very little variance in these factors across the studies. Most used four person categories, four descriptor categories, and an unspecified social referent. Meta-analysis is unpromising under these circumstances.

Second, it makes most sense to us to evaluate such variables experimentally rather than using the correlational approach of metaanalysis. The experimental approach has the advantage of random assignment of subjects to conditions and of holding all potentially confounding factors constant while varying only the one factor of interest. Generality over stimulus materials and individual differences (which is one of the major assets of meta-analysis) can best be obtained through careful replication of the experimental variables with different stimuli and subject types.

\section{PREFERENCE FOR PERSON VERSUS CATEGORY ORGANIZATION}

Another notable finding of this meta-analysis is that in competing category designs people do not prefer category organization over person organization, contrary to what was proposed in the early person organization work. Persons and categories were found overall to be equally effective in the competition for gaining subjects' organizational preference. However, this should not be taken to mean that they are equally preferred under all conditions.

The conditions under which person organization is preferred over category organization for unfamiliar others have been explored experimentally. It has been found that factors determining whether social information will be organized by person or category are the structure of the stimulus field (e.g., Devine \& Ostrom, 1985; McCann, Ostrom, Mitchell, Herstein, \& Pusateri, 1983), exposure frequency (e.g., Pusateri, 1984), subjects' goals or processing objectives (e.g., Ostrom, Carpenter, \& Sedikides, 1986; Pryor et al., 1982), subjects' pre-existing knowledge (e.g., Pusateri, 1984), the schematicity or redundancy of social information (Pryor, Kott, \& Bovee, 1984), and the social referent (Ostrom, Carpenter, \& Sedikides, 1986).

These variables can either enhance the use of person categories or the use of the competing categories. All the above experiments showed this symmetry of effects, which suggests two conclusions. One is that person categories obey the same laws as do nonperson categories. Pairing the outcome of the meta-analysis with this first conclusion leads to the second conclusion. When all of the determinants of category strength are balanced out, person categories are no more preferred than are nonperson categories. Hence, they seem not to hold a privileged position in the organization of social information. 


\section{REFERENCES}

Anderson, J. R. (1983). The architecture of cognition. Cambridge: Harvard University Press. Anderson, J. R., \& Bower, G. H. (1973). Human associative memory. Washington, DC: V. H. Winston and Sons.

Anderson, N. (1962). Application of an additive model to impression formation. Science, $138,817-818$.

Anderson, N. (1981). Foundations of information integration theory. New York: Academic Press.

Asch, S. (1946). Forming impressions of personality. Journal of Abnormal and Social Psychology, 41, 258-290.

Cafferty, T. P., DeNisi, A. S., \& Williams, K. J. (1986). Search and retrieval patterns for performance information: Effects on evaluations of multiple targets. Journal of Personality and Social Psychology, 50, 676-683.

Devine, P. G., \& Ostrom, T. M. (1985). Cognitive mediation of inconsistency discounting. Journal of Personality and Social Psychology, 49, 5-21.

Fiske, S. T., \& Taylor, S. E. (1984). Social cognition. Reading, MA: Addison-Wesley.

Hamilton, D. L., Katz, L. B., \& Leier, V. (1980). Organizational processing in impression formation. In R. Hastie, T. M. Ostrom, E. B. Ebbesen, R. J. Wyer, Jr., D. L. Hamilton, \& D. E. Carlston (Eds.), Person memory: The cognitive bases of social perception. Hillsdale, NJ: Erlbaum.

Hedges, L. V. (1981). Distribution theory for Glass's estimator of effect size and related estimators. Journal of Educational Statistics, 6, 107-128.

Hedges, L. V., \& Olkin, I. (1985). Statistical methodsfor meta-analysis. Orlando: Academic Press.

Heider, F. (1958). The psychology of interpersonal relations. New York: Wiley.

Kintsch, W. (1974). The representation of meaning in memory. Hillsdale, NJ: Erlbaum.

McCann, D. C, Ostrom, T. M., Mitchell, M. L., Herstein, J. A., \& Pusateri, T. P. (1983). Blocking of person information in small social groupings: The formation of person categories. Technical report no. TR/ONR-9, Social Psychology Bulletin 83-1.

Ostrom, T. M., Carpenter, S., \& Sedikides, C. (1986). The cognitive basis of the outgroup homogeneity effect. Unpublished manuscript, Ohio State University.

Ostrom, T. M., Pryor, J. B., \& Simpson, D. D. (1981). The organization of social information. In E. T. Higgins, C. P. Herman, \& M. P. Zanna (Eds.), Social cognition: The Ontario symposium (Vol. 1, pp. 3-38). Hillsdale, NJ: Erlbaum.

Pryor, J. B., \& Ostrom, T. M. (1981). The cognitive organization of social information: A converging-operations approach. Journal of Personality and Social Psychology, 41, 628-641.

Pryor, J. B., Kott, T. L., \& Bovee, G. R. (1984). The influence of information redundancy upon the use of traits and persons as organizing categories. Journal of Experimental Social Psychology, 20, 246-262.

Pryor, J. B., Simpson, D. D.7 Mitchell, M., Ostrom, T. M., \& Lydon, J. (1982). Structural selectivity in the retrieval of social information. Social Cognition, 1, 336-357.

Pusateri, T. P. (1984). The formation of distinct memories of unfamiliar persons. Unpublished doctoral dissertation, Ohio State University.

Roencker, D., Thompson, C, \& Brown; S. (1971). Comparisons of measures for the estimation of clustering in free recall. Psychological Bulletin, 76, 45-48.

Rosch, E. (1973). On the internal structure of perceptual and semantic categories. In T. E. Moore (Ed.), Cognitive development and the acquisition of language. New York: Academic Press.

Rosenthal, R. (1978). Combining results of independent studies. Psychological Bulletin, 85, 185-193. 
Rosenthal, R. (1979). The "file drawer problem" and tolerance for null results. Psychological Bulletin, 86, 638-641.

Rosenthal, R. (1984). Meta-analytic procedures for social research. Beverly Hills, CA: Sage.

Schneider, D. J. (1973). Implicit personality theory: A review. Psychological Bulletin, 79, 294-309.

Srull, T. K. (1984). Methodological techniques for the study of person memory and social cognition. In R. S. Wyer, Jr., \& T. K. Srull (Eds.), Handbook of social cognition (Vol. 2, pp. 1-72). Hillsdale, NJ: Erlbaum.

Srull, T. K., \& Brand, J. R (1983). Memory for information about persons: The effects of encoding operations upon subsequent retrieval. Journal of Verbal Learning and Verbal Behavior, 22, 219-230.

Taylor, S. E., \& Crocker, J. (1981). Schematic bases of social information processing. In E. T. Higgins, C. A. Herman, \& M. P. Zanna (Eds.), Social cognition: The Ontario symposium (Vol. 1, pp. 89-134). Hillsdale, NJ: Erlbaum.

Wishner, J. (1960). Reanalysis of "impression of personality." Psychological Revieiv, 67, 96-112.

Wyer, R. S., \& Gordon, S. E. (1984). The cognitive representation of social information. In R. S. Wyer, Jr., \& T. K. Srull (Eds.), Handbook of social cognition (Vol. 2, pp. 73-150). Hillsdale, NJ: Erlbaum.

\section{APPENDIX \\ STUDIES USED IN THE META-ANALYSIS}

Carpenter, S. L., \& Ostrom, T. M. (1985). The perception of outgroup homogeneity: Differential information organization. Paper presented at the 57th annual meeting of the Midwestern Psychological Association, Chicago, IL, May.

Cafferty, T. P., DeNisi, A. S., \& Williams, K. J. (1986). Search and retrieval patterns for performance information: Effects on evaluations of multiple targets. Journal of Personality and Social Psychology, 50, 676-683 (Study 2).

Devine, P. G., \& Ostrom, T. M. (1985). Cognitive mediation of inconsistency discounting. Journal of Personality and Social Psychology, 49, 5-21 (Study 1).

Devine, P. G., \& Ostrom, T. M. (1985). Cognitive mediation of inconsistency discounting. Journal of Personality and Social Psychology, 49, 5-21 (Study 2).

Devine, P. G., \& Sedikides, C. (1986). Cognitive organization of social information during anticipated interaction. Unpublished manuscript, University of Wisconsin, Madison.

Devine, P. G., Sedikides, C, \& Fuhrman, R. W. (1987). Goals in social information processing. Unpublished manuscript, Ohio State University.

Herren, L. T. (1985). Individual differences in the organization of social information by persons. Unpublished master's thesis (Study 1), Ohio State University.

Herren, L. T. (1985). Individual differences in the organization of social information by persons. Unpublished master's thesis (Study 2), Ohio State University.

Lynn, M., Shavitt, S., \& Ostrom, T. M. (1985). Effects of pictures on the organization and recall of social information. Journal of Personality and Social Psychology, 49, 1160-1168.

McCann, D. C, Ostrom, T. M., Tyner, L. K., Mitchell, M. L. (1985). Person perception in heterogeneous groups. Journal of Personality and Social Psychology, 49, 14491459 (Study 2).

McCann, D. C, Ostrom, T. M., Mitchell, M. L., Herstein, J. A., \& Pusateri, T. P. (1983). Blocking of person information in small social groupings: The formation of person 
categories. Technical report no TR/ONR-9, SocialPsychology Bulletin 83-1.

Mitchell, M. L. (1982). The effect of person familiarity on the organization of social information. Unpublished doctoral dissertation (Study 1), Ohio State University.

Mitchell, M. L. (1982). The effect of person familiarity on the organization of social information. Unpublished doctoral dissertation (Study 2), Ohio State University.

Mitchell, M. L. (1982). The effect of person familiarity on the organization of social information. Unpublished doctoral dissertation (Study 3), Ohio State University.

Mitchell, M. L., Ostrom, T. M., \& Herstein, J. A. (1981a). The effect of blocking and inter-item associative strength on person organization. Laboratory report \#1. Ohio State University.

Mitchell, M. L., Ostrom, T. M., \& Herstein, J. A. (1981b). The effect of blocking and medium on person organization. Laboratory report \#2. Ohio State University.

Mitchell, M. L., Ostrom, T. M., \& Herstein, J. A. (1981c). The effect of ingroup-ingroup status and cognitive set on person organization. Laboratory report \#3. Ohio State University.

Ostrom, T. M., Carpenter, S., \& Sedikides, C. (1986). The cognitive basis of the outgroup homogeneity effect. Unpublished manuscript, Ohio State University.

Ostrom, T. M., Pryor, J. B., Pusateri, T. P., \& Mitchell, M. L. (1986). Social consequences of person organization. Unpublished manuscript (Study 2), Ohio State University.

Ostrom, T. M., Pryor, J. B., Pusateri, T. P., \& Mitchell, M. L. (1986). Social consequences of person organization. Unpublished manuscript (Study 3), Ohio State University.

Ostrom, T. M., Pryor, J. B., Simpson, D. D., Devine, P. J., Dukerkh, J. M., \& Jost, L. (1984). Familiarity and person organization. Unpublished manuscript (Study 1), Ohio State University.

Ostrom, T. M., Pryor, J. B., Simpson, D. D., Devine, P. J., Dukerich, J. M., \& Jost L. (1984). Familiarity and person organization. Unpublished manuscript (Study 2), Ohio State University.

Pfeifer, S. A., McCann, D., \& Ostrom, T. M. (1982). Person organization: The effects of blocking and familiarity. Laboratory report \#5. Ohio State University.

Pryor, J. B. (1986). Multiple nesting. Unpublished manuscript, Illinois State University.

Pryor, J. B., Kott, T. L., \& Bovee, G. R. (1984). The influence of information redundancy upon the use of traits and persons as organizing categories. Journalof Experimental Social Psychology, 20, 246-262.

Pryor, J. B., \& Ostrom, T. M. (1981). The cognitive organization of social information: A converging-operations approach. Journal of Personality and Social Psychology, 41, 628-641 (Study 3).

Pryor, J. B., Simpson, D. D., Mitchell, M., Ostrom, T. M., \& Lydon, J. (1982). Structural selectivity in the retrieval of social information. Social Cognition, 1,336-357 (Study

Pryor, J. B., Simpson, D. D., Mitchell, M., Ostrom, T. M., \& Lydon, J. (1982). Structural selectivity in the retrieval of social information. Social Cognition, 1,336-357 (Study 2).

Pryor, J. B., Simpson, D. D., Mitchell, M., Ostrom, T. M., \& Lydon, J. (1982). Structural selectivity in the retrieval of social information. Social Cognition, 1,336-357 (Study 3).

Pusateri, T. P. (1984). The formation of distinct memories of unfamiliar persons. Unpublished doctoral dissertation (Study 1), Ohio State University.

Pusateri, T. P. (1984). The formation of distinct memories of unfamiliar persons. Unpublished doctoral dissertation (Study 2), Ohio State University.

Pusateri, T. P. (1984). The information of unfamiliar persons. Unpublished doctoral dissertation (Study 3), Ohio State University. 
Pusateri, T. P. (1984). The formation of distinct memories of unfamiliar persons. Unpublished doctoral dissertation (Study 4), Ohio State University.

Pusateri, T. P., \& Geva, N. (1985). Perceivers' goals in acquiring social information: The costs of attempting cognitive organization. Paper presented at the 57th annual meeting of the Midwestern Psychological Association, Chicago, IL, May.

Pusateri, T. P., \& Ostrom, T. M. (1984). Person focus affects personality ratings, occupational rankings, and attributions. Paper presented at the 92nd Annual Meeting of the American Psychological Association, Toronto, August.

Pusateri, T. P., Ostrom, T. M., Devine, P. G., McCann, C. D., \& Mitchell, M. L. (1984). Blocking and preexisting knowledge structures independently facilitate the organization of social information. Unpublished manuscript (Study 1), Ohio State University.

Pusateri, T. P., Ostrom, T. M., Devine, P. G., McCann, C. D., \& Mitchell, M. L. (1984). Blocking and preexisting knowledge structures independently facilitate the organization of social information. Unpublished manuscript (Study 2), Ohio State University.

Sedikides, C, \& Ostrom, T. M. (1986a). Status and ingroup/outgroup membership as determinants of person organization. Paper presented at the 58th annual meeting of the Midwestern Psychological Association, Chicago, IL, May.

Sedikides, C, \& Ostrom, T. M. (1986b). Salience and organization of ingroup/outgroup information. Unpublished data, Ohio State University.

Sedikides, C, \& Ostrom, T. M. (1986c). The role of nonstereotypic information in the organization of ingroup-outgroup information. Unpublished data, Ohio State University.

Sedikides, C, \& Ostrom, T. M. (1987). Familiarity as a mediator of the outgroup homogeneity effect. Paper presented at the 59th annual meeting of the Midwestern Psychological Association, Chicago, IL, May.

Simpson, D. D. (1979). Four empirical investigations of organization of person information in memory. Unpublished doctoral dissertation (Study 2), Ohio State University.

Simpson, D. D. (1979). Four empirical investigations of organization of person information in memory. Unpublished doctoral dissertation (Study 3), Ohio State University.

Simpson, D. D. (1979). Four empirical investigations of organization of person information in memory. Unpublished doctoral dissertation (Study 4), Ohio State University. 